\title{
A Closer Look at the Fire Extinguishing Properties of Water Mist
}

\author{
J. R. MAWHINNEY, B. Z. DLUGOGORSKI and A. K. KIM \\ Institute for Research in Construction \\ National Research Council Canada \\ Ottawa K1A OR6
}

\begin{abstract}
Fire suppression with water mist is widely considered to be an alternative to gaseous fire suppression agents. Much commercial activity has occurred in the last 5 years to develop technology for fire suppression systems based on water mist. Although researchers in the 1950's recognized the dominant mechanisms of extinguishment, recent experimental work has improved the understanding of the extinguishing properties of water mist. This paper proposes a classification terminology for water mists to facilitate discussion of water mist systems. It describes the primary mechanisms of extinguishment, namely heat extraction, oxygen displacement, and radiation attenuation, and invokes theoretical considerations of vapour/air mixture dilution and kinetic effects at the molecular level. Evidence of an effect of invigoration of combustion caused by the introduction of water mist is presented. Not all fires are extinguished rapidly by water mist: the time to extinguish a fire is a function of fuel type, geometry and mist characteristics. An understanding of the suppression properties of water mist allows a designer to make reasonable choices in designing a suppression system for a particular fire scenario, and is essential for the development of algorithms for computer models of water mist suppression systems.
\end{abstract}

KEYWORDS: combustion, fire suppression, water mist

\section{INTRODUCTION}

The use of very fine water sprays (referred to as "water mist" in this paper) to extinguish fires has received much renewed attention in the last decade. It is "renewed attention," because considerable attention was given to studying the potential for fire suppression with water mist in the 1950's. The stated objectives of two studies that were done by Braidech [1], and Rasbash, et. al. [2] were to understand the mechanisms of using very small droplets to extinguish fires, and to identify the limits of performance of fine spray as an extinguishing agent. These early studies confirmed that finely divided water sprays were more efficient than coarser sprays at absorbing heat, and that the mechanisms of flame cooling and oxygen 
displacement by steam were the dominant mechanisms of extinguishment, particularly with liquid fuel pool fires.

Despite the level of understanding evident in those early studies, it was not considered practical to design fire suppression systems, based entirely on using very fine sprays, until recently. The advantage of using fairly large drop sizes produced by standard sprinklers outweighed the benefits of using fine sprays. The "coarse" sprinkler sprays, delivered from the ceiling, were able to penetrate a fire plume to reach the base of the fire, and worked well for most ordinary combustibles. In contrast, the success of very fine sprays required that more attention be paid to nozzle type, location, compartment ventilation, and the type of fuel. Furthermore, the cost of generating higher water pressure, relative to everyday pumping capacities at that time, and of protecting small orifices from plugging, raised concerns about the economics and reliability of mist systems. Finally the introduction of Halon in the early 1960 's eclipsed the need for any refinements in extinguishing either electrical fires or flammable liquid fires, which are the fire scenarios most likely to benefit from the reduced water requirements of a mist system. It was not until the recent withdrawal of halon for environmental reasons, and an extension of the application of fixed fire suppression systems into domains not previously protected, such as aircraft and ships, that the economics and reliability "equation" changed sufficiently to renew interest in water mist as a fire suppression agent.

A few studies were carried out in the 1970's to explore the use of fine sprays for special applications such as explosion suppression $[3,4]$, and liquid fuel fires in submarines $[5,6]$. In the mid-1980's, large and influential regulatory agencies began to study water mist for a variety of other special applications. These agencies include the Civil Aviation Authority in the UK, the Federal Aviation Authority (FAA) in the USA [7], and the International Maritime Organization (IMO). Their incentive was to generate a low water demand, life-safety system for application in situations where water storage capacity was limited, such that standard sprinkler systems were not feasible. Recently, international pressure to discontinue the use of halons has inspired a fierce search for a benign alternative fire suppression agent, one that will not in the future be identified as having some hitherto unknown undesirable quality. These circumstances changed the economic conditions that previously led to the "shelving" of water mist. With the emergence of a new need, and relaxed economic constraints, there was an incentive to adapt reliable pumping and filtering technologies from other industrial domains to the problem of fire suppression.

The renewed interest in water mist for fire suppression has been accelerating since 1990. In the commercial milieu, a new community of fire suppression equipment manufacturers has been established. In the regulatory forum, the National Fire Protection Association (NFPA), and IM are preparing engineering standards. There are a score of research programs by private and public agencies in Europe and North America to develop water mist technology to the point that it can be widely marketed.

One such public program has been at the National Research Council Canada, in the Institute for Research in Construction's National Fire Laboratory (NFL), with support from the Canadian Navy. Several papers have been written in the last year based on the NFL research project, identifying engineering criteria for the design of water mist fire suppression systems. Those papers attempted to combine an understanding of the "physics", or dynamics, of extinguishment, mist generation, and compartment factors, with practical aspects of applying the technology in shipboard situations. The criteria divide into distinct subject areas, such as fire scenario, spray characteristics, and nozzle design, any one of which warrants expanded discussion. In this paper, one of those subject areas will be expanded, that of the extinguishing properties of water mist. The discussion will not be rigorous in terms of analyzing heat transfer or combustion chemistry, but it will provide a qualitative expression of what appears to be happening, and will discuss the implications of that understanding for the design of water mist systems. 


\section{DEFINING WATER MIST}

For the purpose of facilitating discussion of the extinguishing properties of water mist, this paper proposes a terminology for distinguishing between "coarser" and "finer" water sprays. Using a "cumulative percent volume" distribution plot to represent the drop size distribution [8, 9], three gradations of water spray are identified in Figure 1. The terms Dv0.1 and Dv0.9 refer to the diameters for which 10 percent, or 90 percent, respectively, of the volume of the spray is contained in droplets with smaller diameters, measured in a standard manner [11, 12].

(A drop size distribution is not a constant for all locations in a spray. For purposes of comparing the drop size distribution produced by different nozzles, it is necessary to select a standard reference point for measuring it. The NRCC approach is to measure three drop size distributions, at a distance of $1 \mathrm{~m}$ from the tip of the nozzle, at $0^{\circ}, 15^{\circ}$ and $30^{\circ}$ radially from the vertical central axis, and to plot the envelope curves as described in [12].)

The cumulative percent volume distribution curve for a "Class 1" water spray will plot entirely to the left of the line connecting Dv0.1 $=100$ microns and Dv0.9 $=200$ microns. The cumulative percent volume distribution curve for a "Class 2" water spray will lie entirely to the left of the line connecting Dv0.1 $=200$ microns and Dv0.9 $=400$ microns. A distribution curve that extends to the right of that line is considered a "Class 3" water spray. This classification system is intended to provide a useful, but not "scientific," distinction between sprays of different drop size characteristics. It will no doubt be challenged, because any numerical cut-off point is unavoidably arbitrary. It is nevertheless useful for purposes of discussion.

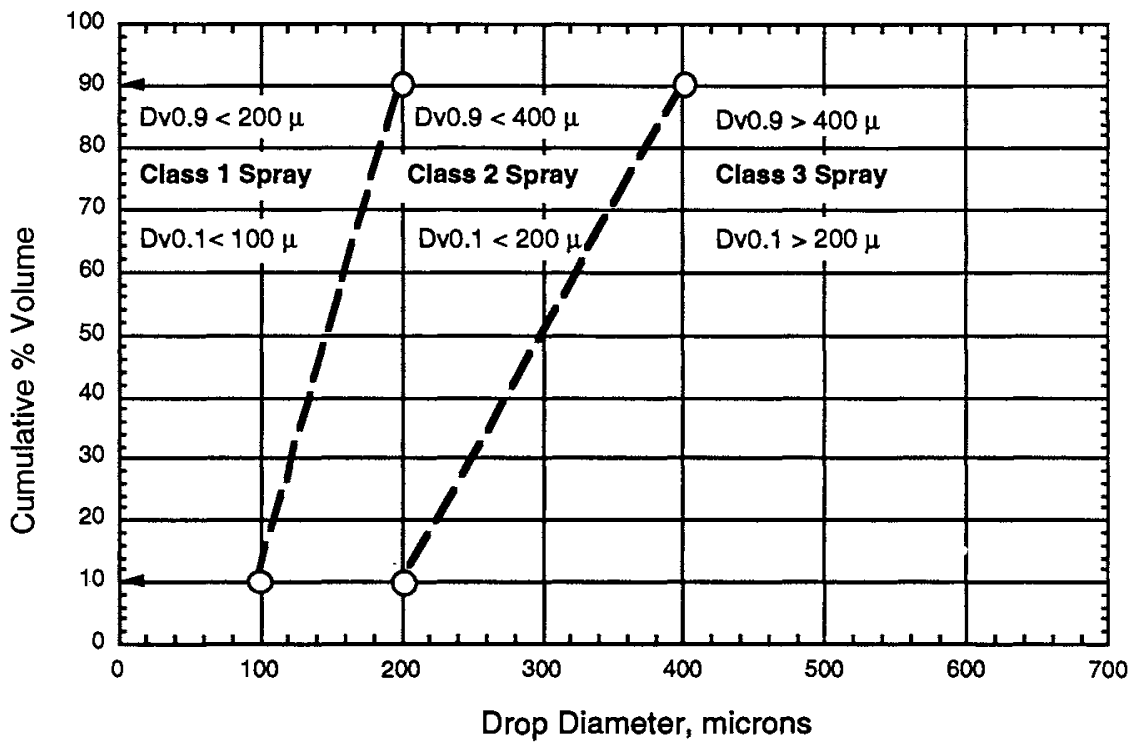

FIGURE 1. Proposed classification of water sprays by dropsize distribution 
The term "mist" in this paper applies to Class 1 and Class 2 water sprays, which have at least 90 percent of the spray volume in drops with diameters smaller than 400 microns. It is recognized that all water sprays contain a certain percentage of "fine" drop sizes, which will provide some of the benefits of a rapid evaporation and heat absorption. Mist, however, is distinguished by being composed almost entirely of "fine" drop sizes, which evaporate rapidly, resulting in flame cooling and in extinguishment through oxygen displacement. Class 1 and Class 2 sprays can be applied to liquid fuel fires without causing serious splashing [1,2], or in situations in which fuel wetting should be limited. For situations that can tolerate application of more water, and perhaps actually require fuel wetting to achieve extinguishment, Class 3 sprays may be the preferred choice.

\section{EXTINGUISHING PROPERTIES OF WATER MIST}

A basic description of how water mist extinguishes fires was provided as early as 1955 by Braidech [1] and confirmed by Rasbash [2]. To quote Braidech:

"The extinguishing action of sprays of finely divided water applied to commonly encountered fires appears to be due pre-dominantly to dilution of the air (oxygen) supply in the zone of burning with vapour (steam) resulting from evaporation of water droplets in the heated area surrounding the fire. The cooling effects of the water may also be important factors in extinguishment in many cases. In order to obtain extinguishment, the water droplets comprising the spray must be relatively small, and the amount of water applied must be adequate in relation to the specific fire."

Research conducted four decades later has not altered the accuracy of this description. The recent work has, however, suggested other less predictable processes that appear to be involved, and clarified the importance of the dominant mechanisms for design of effective fire suppression systems.

This author described three mechanisms which act together to extinguish fire $[8,11]$. These were identified as 1) heat extraction, 2) oxygen displacement, and 3) blocking of radiant heat. Wighus [13] and Hanauska [14] described the mechanisms as "gas phase cooling and steam inerting," but make no reference to radiant heat attenuation. Although all three mechanisms are involved to some degree in every extinguishment, it was evident in the NRCC experiments that some fires were extinguished predominantly through heat extraction (cooling), and others predominantly through displacement of oxygen. The difference depended on whether the fire was poorly or well ventilated and the properties of the fuel. From theoretical considerations, there are other mechanisms that play a role in extinguishment, but it is difficult to quantify their importance. The benefit of radiation attenuation in the compartment is evident in reduced thermal feedback to burning and unburned fuel surfaces. In the NRCC experiments, however, there was no single fire test in which radiation attenuation could be identified as the dominant mechanism of extinguishment. The dilution of vapour/air mixtures by the mixing of water vapour and entrained air in the flammable vapour zone above a fuel surface should have some effect for pool and spray fires. Also, the velocity of the flame front in a flammable gas mixture may be inhibited (or accelerated) by the presence of small water droplets dispersed in a volume of flame, and this phenomenon may play a role in the extinguishment of spray fires and in inhibiting deflagrations [15].

For engineering purposes, particularly the design of reliable water mist fire suppression systems, it may be sufficient to understand the three dominant mechanisms, namely, heat extraction, oxygen displacement, and radiation attenuation. For scientific purposes, computer modellers need to understand all extinguishing mechanisms to develop algorithms to simulate 
the extinction of fire by mist. An ideal computer model would account for heat extraction, oxygen reduction, concentration changes in vapour/air mixtures, and kinetic effects at the molecular level. No such model exists at this time.

The three dominant mechanisms of extinguishment were summarized in previous papers [11, 12]. This paper also discusses two less predictable extinguishing properties of vapour/air dilution and kinetic effects, and explores the implications of all of the suggested mechanisms. Table 1 summarizes the points to be discussed.

\section{Heat Extraction (Cooling)}

When water is applied to a fire, heat is absorbed in three areas: from the hot gases and flames; from the fuel; and from the objects and surfaces in the vicinity of the fire. Cooling of the fuel and nearby objects contributes to reducing fire spread, but it does not necessarily require fine drop sizes. In fact, wetting and cooling of solid fuels is easier to achieve by using larger droplets ( $>400$ microns) and delivering more water than can usually be delivered as water mist.

The primary advantage of water mist (Class 1 and 2 sprays) over coarser (Class 3 ) sprays is to enhance the speed at which the spray extracts heat from the hot gases and flame, using a lower total volume of water. The conversion of water droplets to steam in a diffusion flame absorbs heat. If sufficient heat is withdrawn, the gas-phase temperature can be dropped below that necessary to sustain the combustion reaction, and flame will be extinguished. Theoretical considerations suggest that the combustion reaction in a diffusion flame will cease if the flame temperature drops below approximately $1600^{\circ} \mathrm{K}\left(1327^{\circ} \mathrm{C}\right)[16]$.

As for what constitutes "sufficient" heat absorption, various authors note that it is not necessary to absorb all of the heat given off by the fire at the rate of burning. Absorbing 30-60 percent may be enough to cause burning to stop [13]. An estimate of the minimum evaporation rate to extinguish a fire of a given heat release rate (HRR), calculated on the basis of the absorption of the heat given off by the fire, is of little practical value, however, because extinguishment usually involves more than just flame cooling. The concurrent effect of oxygen reduction could mean the fire could be extinguished with only a fraction of the theoretical minimum required for flame cooling.

For liquid fuel fires, the evaporation of mist cools the flame, which in turn reduces the radiant heat flux to the surface of the fuel, resulting in a reduction in the evolution of flammable vapours. The combination of reduced flame temperature and reduced evolution of vapours results in a reduced burning rate and, in some cases, complete extinction. Fires in liquid fuels with flash points (FP) above normal ambient temperatures, for example 'diesel' fuel (FP $\approx$ $60^{\circ} \mathrm{C}$ ), can be extinguished relatively easily by flame cooling. Fires in liquid fuels with flash points below normal ambient temperatures, such as heptane $\left(\mathrm{C}_{7} \mathrm{H}_{16}, \mathrm{FP} \approx-4^{\circ} \mathrm{C}\right)$ are much harder to extinguish by cooling alone because temperatures cannot be reduced enough to reduce the vapour/air mixture above the surface of the fuel to below the lean flammability limit [17]. Any hot object or fragment of flame above the fuel surface can cause re-ignition.

The cooling of flames above solid fuels also reduces the radiant heat flux to the fuel surface and the rate of pyrolysis of the fuel. With charring substances, however, the primary combustion reaction occurs within the carbon-rich porous zone that forms on the fuel surface [16, $p$ 179]. Cooling of the diffusion flame above an established char zone may not be enough to achieve suppression. Either water mist must be applied early in the fire, before a deep char zone has developed, or water droplets must penetrate the char zone and reach the actual interface between burning and unburned fuel. On the other hand, the flame height and plume velocities for glowing combustion are relatively low, so that the larger drop sizes in a Class 1 or Class 2 spray may not be evaporated and will wet the fuel surface. Extinguishment, therefore, depends 
TABLE 1. Mechanisms of extinguishment by water mist, and their application

\begin{tabular}{|c|c|}
\hline MECHANISM & PRINCIPLE OF APPLICATION \\
\hline \multicolumn{2}{|l|}{ PRIMARY } \\
\hline Heat extraction & $\begin{array}{l}\text { The drop size distribution, momentum, and mass } \\
\text { flow rate of the spray delivered to the fire, after } \\
\text { losses to interior surfaces and obstructions, must } \\
\text { be sufficient to absorb a critical percentage of the } \\
\text { heat released by the fire. }\end{array}$ \\
\hline Oxygen displacement & $\begin{array}{l}\text { Design to: } \\
\text { a) enclose fire to contain evaporated water, or } \\
\text { b) use nozzle dynamics to force water vapour } \\
\text { into the base of the fire. }\end{array}$ \\
\hline $\begin{array}{l}\text { Radiant heat attenuation } \\
\text { a) to unburned surfaces } \\
\text { b) to burning surfaces }\end{array}$ & $\begin{array}{l}\text { Mist must } \\
\text { a) envelope or surround the fire, and } \\
\text { b) penetrate the flame. }\end{array}$ \\
\hline \multicolumn{2}{|l|}{ SECONDARY } \\
\hline $\begin{array}{l}\text { Vapour/air dilution } \\
\text { a) by water vapour } \\
\text { b) by entrained air }\end{array}$ & $\begin{array}{l}\text { Significant for liquid fuel pool or spray fires. } \\
\text { Must have enclosure effects or dynamic spray } \\
\text { properties to distribute diluent. } \\
\text { Nozzle design may influence dilution } \\
\text { Difficult to predict or control. }\end{array}$ \\
\hline $\begin{array}{l}\text { Kinetic effects: flame velocity } \\
\text { a) reduce flame velocity } \\
\text { b) accelerate combustion }\end{array}$ & $\begin{array}{l}\text { Applies to deflagration control by reducing } \\
\text { velocity of the flame front, hence explosion } \\
\text { overpressure. } \\
\text { Unpredictable: it may suppress or invigorate } \\
\text { combustion. }\end{array}$ \\
\hline
\end{tabular}

on the geometry of the fuel arrangement and the depth of the char layer, i.e., the length of time the fire has been burning. Exposed surfaces facing the source of the spray might be extinguished, while shielded surfaces (such as within a wood crib) will be almost impossible to extinguish by cooling alone.

Consideration of the mechanism of gas-phase cooling suggests that it is enhanced by having a high percentage of small drop sizes (as for example a Class 1 spray) distributed with enough energy to cause it to mix turbulently but uniformly in all regions of the flame. Because obstructions in a compartment interrupt the mixing process and extract water mass from the spray as mist is deposited on surfaces, the efficiency of gas phase cooling will be reduced in obstructed compartments. It is evident, then, that a suppression scenario that relies on gasphase cooling requires that close attention be paid to the location of nozzles, the direction of application, the drop size distribution and spray momentum, as well as the total mass of water that must be evaporated to extract a critical percentage of the heat produced by the fire. 
Braidech [1] concluded correctly in 1955 that the suppression effect of water mist "appears to be due pre-dominantly to dilution of the air (oxygen) supply in the zone of burning with vapour (steam)..." That is to say, oxygen displacement appears to play a stronger role than flame cooling. Water droplets expand approximately 1900 fold upon evaporating (at $95^{\circ} \mathrm{C}$, 1 atmosphere pressure). If evaporation occurs rapidly, the water vapour displaces the air in the vicinity of the drop. Injection of a finely divided water spray into a hot compartment results in rapid evaporation, expansion, and in displacement of the âir in the compartment by steam. If the amount of oxygen available for combustion is reduced below a critical level, the fire burns inefficiently and will be easier to extinguish by cooling.

Braidech's study, as with most studies of the extinguishment of fires with water mist, concentrates on hydrocarbon pool fires, with a few tests on wood cribs. Recent tests by Wighus et al [13], Mawhinney [12] and Hanauska and Back [14] on diesel and heptane pool and spray fires, confirmed that oxygen displacement ('steam inerting') was the dominant mechanism by which water mist extinguished the flames, both in compartments and in openarea pool fires. The compartmentation allowed the water vapour concentration to build up so that hidden and shielded fires could be extinguished. Hanauska and Back [14] used a Class 1 spray with very low momentum and flow rate to extinguish heptane pool and spray fires, after 30 to 50 seconds of mist application, in a $28 \mathrm{~m}^{3}$ compartment. Fires in such enclosures can be extinguished with about one-tenth the mass flux of water needed for pool fires in open-areas [13]. In open area fire tests at NRCC, extinguishment of pool fires could not be achieved unless the spray was oriented, and applied with enough force, so as to push water vapour created in the outer regions of a flame onto the fuel surface. The open area fires required high momentum sprays, properly oriented. This suggests that the water vapour concentration at the fuel surface can be increased by either confining the fire in an enclosure, or by using spray momentum to push the water vapour against the surface. Of course, the additional mixing created by the higher momentum spray also increased the gas-phase cooling. It is not easy to separate the effects of cooling and oxygen displacement, other than to note that, in the NRCC plenum tests [9], turbulent mixing alone did not bring about extinction if there was no component of the spray velocity directed toward the fuel surface.

The minimum amount of free oxygen needed to support combustion varies with the type of fuel. In general, hydrocarbon gases and vapours cease burning at oxygen concentrations below 13 percent, while charring solid fuels may burn with oxygen concentrations as low as 7 percent [16]. This explains why it is easier to extinguish hydrocarbon pool fires (diesel and heptane) than wood crib fires; the reduction in oxygen needed for extinction of the hydrocarbon flame is easy to obtain compared to that needed to inert a wood fire.

The effects of oxygen displacement also explain why it is easier to extinguish 'large' fires than 'small' fires in a compartment. 'Large' and 'small' are defined loosely in terms of whether the fire will effect the average temperature and oxygen concentrations in the compartment within the activation time of the water mist system. A 'large' fire releases more heat into a compartment in the early stages than a 'small' fire, so that more heat is available to evaporate the fine water droplets. A 'small' fire will have a continuous source of fresh combustion air at normal oxygen concentrations. A 'large' fire will reduce the ambient oxygen concentration to the point that combustion efficiency will be reduced, prior to introducing the water mist. When mist is applied, then, the oxygen dilution occurs more rapidly for the large fire than for the small fire. With the combined effects of vitiated combustion air, plus further dilution by water vapour, 'large' fires can be extinguished with lower flux densities than 'small' fires.

The first commercially developed and marketed water mist fire suppression systems were accepted (by European maritime authorities) on the basis of their ability to suppress machinery room pool and spray fires involving hydrocarbon fuels, usually diesel. The dramatic extinction 
events shown in those tests represented the best case for a water mist fire suppression system, i.e., relatively high flash point fuel; much available heat due to large size of fire; and confinement of the water vapour by an enclosure. To be useful in a compartment that cannot tolerate the damage that could be done by a 'large' fire, however, careful thought must be given as to how to achieve heat extraction and oxygen displacement with small fires early in their development.

\section{Blocking Radiant Heat}

The author included a third mechanism of extinguishment - blocking radiant heat, which stops the fire from spreading to unignited fuel surfaces, and reduces the vaporization or pyrolysis rate at the fuel surface. Radiometer measurements taken during NRCC fire tests showed that the radiant heat flux to the walls of the test compartment were reduced by more than 70 percent by water mist. The reduction was substantial, even in cases"in which the pool fire was not extinguished by the water mist. On a 'macro-scale', then, radiation attenuation provided by water mist protects objects and personnel in a space from radiant heat damage, whether or not extinguishment occurs. On that account, radiant heat blocking is an important benefit of water mist in fires both in compartments and in open areas.

One question that arises is to what extent is the measured reduction in radiant heat to adjacent surfaces due to the cooling and reduced size of the flame, and to what extent is it due to attenuation of the radiant heat through scattering and absorption of thermal energy. Theoretical considerations suggest that mist or steam that enters the space between a flame and the fuel surface will reduce the radiant heat flux to that surface [15]. This is difficult to measure, but it is hypothesized that radiant heat from the flame could be absorbed by unevaporated droplets and steam, which re-radiate at the lower temperature of the droplet or vapour. With liquids such as diesel fuel $\left(\mathrm{FP}=60^{\circ} \mathrm{C}\right)$, this reduction in the heat flux to the fuel surface may reduce the vaporization rate of the liquid fuel and contribute to the extinguishment. The effect would be expected to be less important for liquids with flash points below normal ambient temperatures, such as heptane $\left(\mathrm{FP}=-4^{\circ} \mathrm{C}\right)$.

Radiant heat attenuation between flame and fuel surface is important for computer modelling of fire suppression using Computational Fluid Dynamics (CFD). In developing a CFD model of fire suppression using water mist, An et al [18] calculated the heat release rate of a liquid pool fire, taking into account the coefficient of absorption of water vapour in each control volume. A reduction of radiation heat transfer to the fuel pan was predicted to measurably reduce the vaporization rate, hence the heat release rate of the burning vapours. More experiments are needed to compare measurements of heat flux in this zone, to predictions of radiant heat attenuation obtained using the CFD models.

Recent theoretical work on radiation attenuation by water sprays $[19,20]$, indicates that the attenuation of radiation depends very much on drop diameter and mass density of the droplets. Radiation attenuation may not be large $(<10 \%)$ for drop sizes larger than 100 microns, but it may be much greater $(>50 \%$ ) for drop sizes less than 50 microns in diameter. It is possible for more than 30 percent by volume of a Class 1 or even Class 2 spray to be in drop sizes less than 50 microns. An interesting set of 4 experiments that could be conducted then is to test the hypothesis that drop sizes less than 50 microns are more effective at blocking radiant heat than larger drops (given the same mass distribution). Laboratory tests could be conducted to measure the degree of reduction in radiant heat flux through mist clouds composed of different volume concentrations of drops smaller than 50 microns, using a constant radiant heat source that is unaffected by the presence of the mist. It will be necessary to control the path length of the radiant heat as well as the mist density, i.e., the mass of water per unit volume suspended in the air, and the drop size distribution. The difficulty is that as the number of very small 
drops increases, i.e., the spray becomes 'finer', the mass concentration of the spray decreases as well.

\section{OTHER EXTINGUISHING PROPERTIES AND CONTRARY EFFECTS}

\section{Dilution of Vapour/Air Mixture}

Air entrained in a water spray may dilute the vapour/air mixture to below the lean flammability limit. With diesel fuels $\left(\mathrm{FP}=60^{\circ} \mathrm{C}\right)$, a reduction in the rate of vaporization due to cooling, coupled with a dilution of the vapours by the addition of entrained air, may reduce the vapour/air concentration below the lean flammability limit. In contrast, it is much harder to reduce the heptane/air mixture to below its lean flammability limit, because of the low flash point temperature and high vapour pressure. Dilution of pyrolized vapours may also be of benefit for solid fuels. In practical terms, it requires uniform mixing of mist and entrained air throughout the space between the flame and the fuel surface, to dilute all of the vapour/air mixture within the vaporization region. Usually, mixing at the fuel surface is turbulent and non-uniform, so it is likely that there will always be some region of the vapour/air cloud that is in the flammable range.

For purposes of designing suppression systems, it is not yet feasible to quantify the relationship between the flammability limits of different fuels, the fuel vaporization rates, spray evaporation rate, and the mass flow rates of water mist and entrained air. The knowledge of dilution effects can, however, be used to explain differences in suppression performance of water mist on different fuels. It should be possible to calculate dilution effects on gas concentrations using computer field models based on computational fluid dynamics. A field model that incorporates such an algorithm would be a good way to assess the relative importance of this mechanism in fire suppression.

\section{Kinetic Effects of Mist on Flames}

A liquid pool fire is sometimes intensified by the application of water spray. A "flare-up" lasting several seconds may occur at the instant of first contact with the water mist, and it is evident in some fire tests that the burning rate is increased for longer periods. The flare-up at the instant of application of a water spray on liquid fuel fires is familiar to fire-fighters, who are trained not to be startled by the reaction. It is usually followed by a quick knock-down of the flames, and, if conditions are "right", the fire will be extinguished. If conditions are not right (meaning neither gas-phase cooling, oxygen displacement nor vapour dilution is sufficient to extinguish the fire) the fire will continue to burn violently in spite of the mist.

The momentary intensification of the fire has been attributed by some authors to the effect of droplets striking the fuel surface and causing splashing and increased vaporization rate. Kokkala [21] referred to a "flame ball" which occurred when a sprinkler spray (Class 3 spray) hit a hot, high boiling point liquid and explosively vaporized. The same phenomenon was noted by the author, however, during suppression tests in which a Class 1 water mist was applied from below a diesel pan fire in a direction concurrent with the fire plume, such that very few droplets could reach the surface of the diesel fuel [9]. The visual evidence, supported by thermocouple readings, was that the flame within the plenum became violently turbulent and appeared to intensify during the time of application of the mist. One possible explanation for the observed intensification is that the turbulence acted to increase the burning rate of the fuel.

Dlugogorski et al [22] have measured the heat release rate of open area heptane and diesel pan fires during the application of water mist. Figure 2 shows the measurements of heat release 

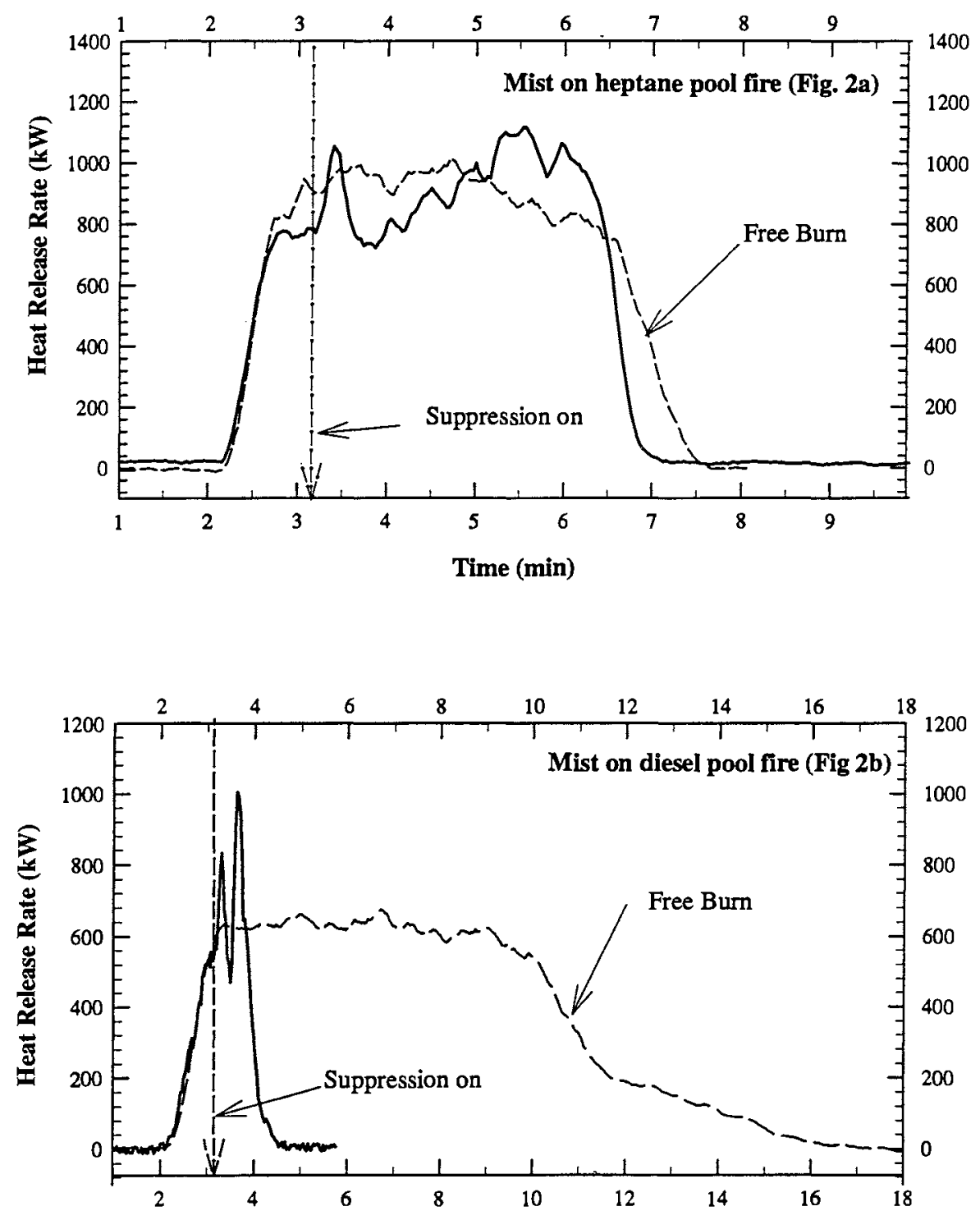

Time, min

FIGURE 2. Plots showing momentary and sustained increases in the heat release rate of heptane and diesel pool fires with application of water mist. 
rate during the suppression of a heptane pool fire and a diesel pool fire, using the same downward-oriented Class 2 water spray in both cases. The HRR curves under suppressed conditions are plotted with the curves for unsuppressed fires in the same pans. In the case of diesel fuel, there is a brief "spike" in the HRR, followed by complete extinguishment within $60 \mathrm{~s}$. For the heptane fire, a brief "spike" also occurred, followed by a partial suppression of the fire, and then by a continued increase in the burning rate of the heptane. The water spray failed to extinguish the fire, and turbulent flaming continued until the fuel was consumed. The maximum HRR of the fire with mist exceeded the maximum for the unsuppressed fire.

Jones and Thomas [15] report similar intensification of the rate of combustion in use of water mists to quench gaseous explosions. The mist suppresses the maximum overpressure in an enclosed gaseous ignition, but the peak pressure may be attained sooner than for an unsuppressed explosion. Furthermore, the authors report that it is "never immediately obvious whether application of a water spray will quell or invigorate an explosion". The conflicting influences of cooling, inerting, dilution and enhanced turbulence and fuel mixing, lead to a degree of unpredictability in the effects of water mist on gas-phase burning.

There could be reason to be concerned that a water mist system that is "under-designed" (that is, unable to extinguish a liquid fuel pool or spray fire) could increase the heat release rate of the fire. A worthwhile research project would be to investigate the conditions under which flare-up or flame invigoration occurs, and to determine whether the overall heat release rate can be increased in a partially suppressed fire burning in a mist.

\section{Time to Extinguishment}

The time needed to extinguish a fire with water mist will vary with the fuel type, compartment geometry, and the drop size distribution, momentum and application rate of the water mist. There have been many demonstrations in which water mist extinguishes liquid fuel pool fires in 10 to $20 \mathrm{~s}$, using small amounts of water. Figure 2, for example, shows a $600 \mathrm{~kW}$, unenclosed diesel pool fire that was extinguished in less than $30 \mathrm{~s}$ by a Class 2 water mist. Such successes occur in circumstances in which all suppression properties act together oxygen displacement, flame cooling, radiant heat blocking and vapour dilution.

It would be a mistake to expect that such rapid extinguishment is a necessary characteristic of all water mist fire suppression systems. There are circumstances in which it can take several minutes to extinguish a fire, without it being considered a "failure". One example is where flame cooling cannot extinguish the fire immediately, but, after several minutes, the build-up of water vapour in the compartment combines with flame cooling to bring about extinguishment. With combustibles that form a char layer, such as fabric, wood, plastics, or electrical wiring in a cabinet, the fire may not be extinguished immediately; but, after a time, fuel wetting begins to reduce the size of the fire and it is eventually extinguished. As long as the mist cools the compartment and protects against thermal damage to adjacent objects, the level of fire control can be considered adequate. Madrzykowski and Vettori [23], describe an algorithm for suppression of fire in office furniture packages burned in an open space, using typical sprinkler sprays. The algorithm calculates the Heat Release Rate of the fire at time $t$ after activation of sprinklers, and is based on empirical relationships established by extensive fire testing. The "time to extinguish" is then the value of $t$ when the HRR drops to zero. The empirical coefficients in the algorithm are specific to the fuel type, sprinkler application rate, and compartment conditions (open area). It would be valuable to develop similar empirical suppression algorithms for the time to extinguish fires in different fuels in compartments, using water mist.

It is usually necessary to flow water from a system for a longer period of time than the extinguishing time. The flow should not be stopped until it is confirmed that a fire has been extinguished. Many of the commercial demonstrations that show, for example, a fire 
extinguished "in $10 \mathrm{~s}$ with less than $1 \mathrm{~L}$ of water", were conducted with an observer's hand on the shut-off valve for the water. This would not be the case in most fixed systems, for which extinguishment must be determined by inspection. The flow duration for actual systems, then, will be determined by the user's ability to obtain information about the status of the fire in the compartment. Some commercial systems are designed for repeated short duration sprays, using automatic valves operated by timers, as a way to limit overall water usage even with delayed human intervention.

\section{CONCLUSION}

The term "applied science" is often used to describe engineering. A fire safety engineer intending to design a water mist fire suppression system for a specific fire scenario must apply the scientific knowledge of how water mist extinguishes fire in order to arrive at a reasonable design. The "first principles" of the suppression properties of water mist described in this paper, can be used to "guide the design" of a water mist fire suppression system, that is, assist in selection of appropriate nozzles, flux densities and spray characteristics, and define the probable performance of the system. The fuel type, pre-burn time and compartment conditions, for example, will dictate what kind of spray will be best, and whether suppression can be achieved with oxygen displacement and flame cooling, or whether fuel-wetting will be required. The state-of-the-art for design of water mist fire suppression systems is not yet at the point that a system can be designed entirely from "first principles", however, and it is wise at this stage to complement analysis with fire testing.

An understanding of the science involved in fire suppression is essential for computer modelling of water mist fire suppression systems. Computer field models require algorithms to quantify the phenomena to be simulated. Algorithms for suppression should incorporate the effects of flame and fuel cooling, oxygen displacement, vapour dilution, reduced radiant heat transfer, and kinetic effects on the combustion process at the molecular level. An ideal model would compute the effects of drop size distribution, mass flux densities, air entrainment rates, and fuel burning characteristics, and recognize the conditions that define extinguishment. Although it is easy to conceptualize these objectives, much more experimental work will be needed to develop and validate the numerical relationships for use in computer field models. 


\section{REFERENCES}

1. Braidech, M.M., Neale, J. A., Matson, A.F. and Dufour, R.E., "The Mechanism of Extinguishment of Fire by Finely Divided Water", Underwriters Laboratories Inc. for the National Board of Fire Underwriters, N.Y., 73 p., 1955.

2. Rasbash, D.J., Rogowski, Z.W. and Stark, G.W.V., "Mechanisms of Extinction of Liquid Fuel Fires with Water Sprays", Combustion and Flame, 4, 223-234, 1960.

3. Vincent, G.C. and Howard, W.B., "Hydrocarbon Mist Explosions Part 2: Prevention by Water Fog", Loss Prevention, 10, 55, 1976.

4. Vincent, G.C. and Howard, W.B., "Hydrocarbon Mist Explosions Part 1: Prevention by Explosion Suppression", Loss Prevention, 10, 43, 1976.

5. Lugar, J.R., "Preliminary Test Results of Fine Water Mist Fire Protection Systems Study", David W. Taylor Naval Ship R\&D Center, Maryland, 1979.

6. Lugar, J.R., “Status Report of Fine Water Mist Fire Protection”, David W. Taylor Naval Ship R\&D Center, Maryland, 1980.

7. Hill, R.G., Marker, T.R. and Sarkos, C.P., "Evaluation and Optimization of an OnBoard Water Spray Fire Suppression System in Aircraft", in Water Mist Workshop, March 1-2, 1993: Proceedings, NIST, Gaithersburg, MD, 1993.

8. Mawhinney, J.R. "Engineering Criteria for Water Mist Fire Suppression Systems", in Water Mist Workshop, March 1-2, 1993: Proceedings, NIST, Gaithersburg, MD, 1993.

9. Mawhinney, J.R., "Characteristics of Water Mist for Fire Suppression in Enclosures", in Proceedings of the Halon Alternatives Technical Working Conference, Albuquerque, New Mexico, USA, 1993.

10. American Society for Testing and Materials, "ASTM E-799-87: Standard Practice for Determining Data Criteria and Processing for Liquid Drop Size Analysis", ASTM, 4 pages, 1990.

11. Mawhinney, J.R., "Design of Water Mist Fire Suppression Systems for Shipboard Enclosures", in International Conference on Water Mist Fire Suppression Systems, Borås, Sweden, 1993.

12. Mawhinney, J.R., "Water Mist Fire Suppression Systems for Marine Applications: A Case Study", in Proceedings of IMAS 94: Fire Safety'on Ships - Developments into the 21st Century, Institute of Marine Engineers, London, UK, May 1994.

13. Wighus, Ragnar; Aune, P.; Drangsholt, G. and Stensaas, J. P., "Fine Water Spray System - Extinguishing Tests in Medium and Full Scale Turbine hood", SINTEF NBL Norwegian Fire Research Laboratory, under contract to Ginge-Kerr Offshore, July, 1993.

14. Hanauska, C.P. and Back, G.G., "Halons: Alternative Fire Protection Systems, An Overview of Water Mist Fire Suppression Systems Technology", Hughes Associates, Inc., Columbia, MD, 1993. 
15. Jones, A. and Thomas, G.O., "The Action of Water Sprays on Fires and Explosions", Transactions of the Institution of Chemical Engineers, 71: Part B, 41-49, 1993.

16. Drysdale, D., An Introduction to Fire Dynamics, 1st ed., pp. 222-225, John Wiley and Sons, New York, 1985.

17. Kanury, A.M., "Ignition of Liquid Fuels", in SFPE Handbook of Fire Protection Engineering, ed. P.J. DiNenno et al, p. I-315-I-325, National Fire Protection Association, Quincy, MA, 1988.

18. An, M.W., Sousa, A.C.M. and Venart, J.E.S., "Modeling of a Shipboard Waterfog Fire Suppression System", University of New Brunswick. Report No. 991-1042-2045, Fredericton, 1994.

19. Coppalle, A., Nedelka, D. and Bauer, B., "Fire Protection: Water Curtains", Fire Safety Journal, 20, 241-255, 1993.

20. Ravigururajan, T.E. and Beltrav, M.P., "A Model for Attenuation of Fire Radiation through Water Droplets", Fire Safety Journal, 15: 2, 171-181, 1989.

21. Kokkala, M.A., "Extinction of Liquid Pool Fires with Sprinklers and Water Sprays", Valtion Teknillinen Tutkimuskeskus, Statens Teniska Forskningscentral (Technical Research Centre of Finland), Espoo, 1989.

22. Dlugogorski, B.Z., and Kim, A.K., private communication, National Fire Laboratory, National Research Council Canada, 1994.

23. Madrzykowski, D. and Vettori, R.L., "A Sprinkler Fire Suppression Algorithm for the GSA Engineering Fire Assessment System." U.S. Department of Commerce, Building and Fire Research Laboratory, National Institute for Standards and Technology (NIST), 1992. 